\title{
Integrating Roundabouts with Freight Roadway Networks
}

\author{
Ranjit Prasad Godavarthy', Eugene R. Russell² \\ ${ }^{1}$ Upper Great Plains Transportation Institute, North Dakota State University, Fargo, USA \\ ${ }^{2}$ Department of Civil Engineering, Kansas State University, Manhattan, USA \\ Email: ranjit228@gmail.com, geno@ksu.edu
}

Received 7 September 2015; accepted 21 November 2015; published 24 November 2015

Copyright (C) 2015 by authors and Scientific Research Publishing Inc.

This work is licensed under the Creative Commons Attribution International License (CC BY).

http://creativecommons.org/licenses/by/4.0/

c) (i) Open Access

\section{Abstract}

The demand for freight transportation in the United States has grown rapidly in the past couple of decades; the rate at which the highway capacity is growing is not able to meet the freight-transportation needs, resulting in congestion and delay, ultimately affecting the users and the public with increased prices for the goods delivered, unreliable delivery times, and air-pollution concerns. Freight bottlenecks are a major cause of recurring congestion which accounts for about $40 \%$ of total vehicle hours of delay in the United States. Intersections for urban freight-roadway networks are one of the major freight bottlenecks and are considered to be a significant contributor for congestion and delay. Improving the efficiency at urban intersections with high truck traffic can address the freight-traffic congestion, leading to optimized goods movement as well as decreased delays, congestion, and emissions, thus enhancing the air quality in and around the communities. With the roundabout intersection control being proven as a safe, operationally efficient, and environment-friendly control treatment, a greater use of roundabouts with urban freightroadway networks and their feasibility is analyzed in this study. The control for most urban intersections is a signalized treatment; a performance analysis is conducted for selected signalized intersections in urban freight-roadway networks, comparing the intersections by adapting a roundabout control theoretically using SIDRA (signalized and un-signalized intersection design and research aid) Intersection software. Various parameters, such as the intersection's level of service, the effective intersection capacity, the average control delay, vehicular emissions [carbon dioxide $\left(\mathrm{CO}_{2}\right)$, hydrocarbons ( $\left.\mathrm{HC}\right)$, carbon monoxide ( $\left.\mathrm{CO}\right)$, and nitrogen oxides $\left(\mathrm{NO}_{\mathrm{x}}\right)$ ], the intersection's annual delay, and the intersection's annual cost, are selected for comparison.

\section{Keywords}

Congestion on Roads and Highways, Modern Roundabouts, Truck and Vehicular Emissions 


\section{Background and Literature Review}

A recent study conducted by Federal Highway Administration (FHWA) has estimated that about 40\% of traffic congestion in general, as opposed to freight congestion specifically, is caused by bottlenecks, resulting in stopand-go traffic flow and long backups [1]. The study found that freight bottlenecks caused upwards of 243 million truck hours of delay and that the direct user cost for this delay was about $\$ 7.8$ billion per year. Signalized, arterial intersections account for a total of $18 \%$ of the delay-about 43 million hours of delay-for different freight routes that are comprised of urban freight corridors, intercity freight corridors, truck-access routes, and intermodal connectors[1].

There are also air-pollution concerns as a result of heavy congestion in urban areas. According to Freight Facts and Figures from the Office of Freight Management and Operations [2], diesel-fueled heavy trucks emit small amounts of carbon monoxide (CO) but large amounts of nitrogen oxides $\left(\mathrm{NO}_{\mathrm{x}}\right)$ when compared to gasoline-fueled cars. Freight transportation contributes to $27 \%$ of the total $\mathrm{NO}_{\mathrm{x}}$ emissions and one-third of the particulate-matter emissions that are 10 microns in diameter (PM-10) from mobile sources in the United States. Trucks have a two-third share of the $\mathrm{NO}_{\mathrm{x}}$ emissions from the freight sector. Apart from the above emissions, the transportation sector releases large quantities of greenhouse gases (GHGs), such as carbon dioxide, methane, nitrous oxide, and hydrofluorocarbons, and these gases trap heat in the atmosphere which affects the earth's temperature. Therefore, the increased truck congestion at urban intersections can affect the air quality by the emissions which can be mitigated with better traffic-flow techniques such as less delay at urban intersections $[2]$.

The above challenges clearly show that there is a need to improve traffic flow at interchanges, intersections, and other transportation facilities in order to better accommodate vehicles and trucks with less congestion and delay time, thereby saving many dollars and improving the environment. This study's scope focuses on improving performance and traffic flow while decreasing congestion at intersections with high truck volumes. One of the three strategies to decrease traffic congestion is to operate the existing traffic capacity more efficiently [3]. While most intersections for urban freight-roadway networks (designated roads that are more frequently used by trucks for goods movement) have signalized control, roundabout control can also be considered as a possible solution to improve efficiency as well as to reduce delay and emissions, considering that roundabouts' safety and operational benefits are well documented [4]-[6]. Roundabouts are also conventionally designed for effectively accommodating trucks. Some recent studies have also addressed oversize-overweight vehicles’ accommodation concerns at roundabouts by maintaining roundabout features such as an external truck apron, centerisland truck apron, a custom center-island design, and traversable splitter islands [4] [7]-[10]. Russell et al. [11]-[13] have conducted surveys with trucking agencies that haul heavy trucks in the United States to understand freight bottlenecks on state highways; Russell et al. concluded that intersections with signs or signals were considered as freight bottlenecks by most trucking agencies when compared to a roundabout control. Mandavilli et al. [14] have studied the environmental impact of single-lane and double-lane modern roundabouts in Kansas; the authors found that roundabouts operated more effectively than the previous intersection control (all-way stop control or two-way stop control) to reduce vehicular emissions.

While the environmental impact of roundabouts has been proven with prior research, the environmental impacts of roundabouts in urban freight-roadway networks expecting high truck traffic are not known. According to a 2008 United States Environmental Protection Agency report [15], the average idle emission for light-duty gasoline-fueled vehicles includes 71.22 grams/hr of CO emissions, 3.51 grams/hr of $\mathrm{NO}_{\mathrm{x}}$ emissions, and 3.16 grams/hr of total hydrocarbon (HC) emissions. In contrast, the average idle emissions for heavy-duty, gasolinefueled vehicles include 151.90 grams/hr (113\% more) of CO emissions, 5.33 grams/hr (52\% more) of $\mathrm{NO}_{\mathrm{x}}$ emissions, and 7.26 grams/hr (129\% more) of total hydrocarbon emissions; the average idle emissions for heavy-duty diesel vehicles include 25.63 grams/hr (64\% less) of CO emissions, 33.76 grams/hr (861\% more) of $\mathrm{NO}_{\mathrm{x}}$ emissions, and 3.50 grams/hr (11\% more) of total hydrocarbon emissions [15]. It can be understood from the above numbers that emissions at roundabouts with a high volume of trucks can be substantially high; therefore, the environmental impacts for such roundabouts need to be validated to understand if roundabouts can be included with urban freight-roadway networks.

\section{Study Methodology}

The study's objective was to investigate integrating a greater use of roundabouts for freight roadway networks in 
and around urban areas in order to optimize goods movements as well as to decrease delay, congestion, and emissions, thus enhancing air quality in and around the communities. Most intersections for urban freightroadway networks were signalized intersections; therefore, the delay and emissions for vehicles at signalized intersections were analyzed and theoretically compared to a roundabout to understand if roundabouts can be designed and built at these intersections for better delay and emission reductions.

This comparative analysis was achieved by analyzing various performance measures for selected signalized intersections in urban freight-roadway networks, comparing signalized intersections by adapting a roundabout control theoretically using the SIDRA Intersection software. The analyzed performance measures included intersection level of service (LOS), effective intersection capacity (the ratio of the total intersection demand flow to the intersection's degree of saturation), average control delay (the delay to a vehicle which decelerates from the approach cruise speed to a full stop, waits, and then accelerates to the exiting cruise speed), vehicular emissions $\left[\mathrm{CO}_{2}, \mathrm{HC}, \mathrm{CO}\right.$, and $\left.\mathrm{NO}_{\mathrm{x}}\right]$, the intersection's annual delay, and the intersection's annual cost (the vehicles' operating cost along with the time cost for drivers and passengers). Average control delays and vehicular emissions ( $\mathrm{CO}, \mathrm{HC}, \mathrm{CO}_{2}$, and $\mathrm{NO}_{\mathrm{x}}$ ) were used as key performance measures to make conclusions about the most effective intersection control. SIDRA Intersection is an advanced micro-analytical, traffic-evaluation tool that is used worldwide for intersection capacity, level of service, and performance analysis, this software is the only program known to the authors that is capable of making these comparisons for traditional intersection control vs. roundabouts [16]. SIDRA Intersection version 5.1 was used for this study's performance analysis.

This study was conducted by selecting cities of different sizes, such as a small city, a medium city, and a big city in Kansas, United States based on the area population. The different cities considered were as follows: Manhattan as a small-sized city, Topeka as a medium city, and Overland Park as a big city. City officials for each locale were contacted to obtain the freight roadway networks (when available) or routes that had a high trucking activity. Based on the obtained routes with high trucking activity, intersections which had higher truck usage and reliable traffic-count data were selected to conduct a performance analysis with the SIDRA Intersection software.

\subsection{Small City: Manhattan, Kansas}

The City of Manhattan did not have a developed freight roadway network to identify the roads that were heavily used by trucks. However, staff from the city traffic engineer's office helped to identify six signalized intersections (listed in Table 1) that expect high truck traffic. These six signalized intersections had traffic counts available from the city traffic engineer which were used to calculate the peak-hour factor; however, the data were not useful for SIDRA Intersection analysis because directional traffic counts (the number of left-turning, through-movement, and right-turning vehicles) were not available for each approach at an intersection. Therefore, manual traffic counts were conducted at all six intersections to obtain directional traffic counts, the percentage of trucks using the intersection, signal phasing, and signal timing.

The performance of the six signalized intersections was analyzed using the SIDRA Intersection software and was theoretically compared with a roundabout control for the same traffic-count data and percentage of trucks by using the SIDRA Intersection software; the results are presented in Table 1 and Table 2. The procedure for conducting the performance analysis is explained and demonstrated in the following section. The results for the performance analysis are summarized in Table 1 and Table 2. For all six intersections that were studied in Manhattan, the roundabout control proved to have better LOS, more effective intersection capacity, less control delay, fewer emissions, and a better annual intersection performance when compared to the signalized control.

\section{Performance Comparison of Signalized Intersection Control with Roundabout Control Using the Sidra Intersection Software}

The theoretical performance-comparison procedure for a signalized intersection with a roundabout control that utilizes the SIDRA Intersection software is demonstrated by using the McCall Road and Hays Drive signalized intersection in Manhattan, Kansas. Initially, the geometry of the signalized intersection was studied (on site and/or using Google maps), and an intersection was designed in the SIDRA Intersection software with details such as the number of lanes, the lane length, and the lane configuration for each intersection approach.

Part a of Figure 1 shows the Google map for the McCall Road and Hays Drive intersection, and part b of Figure 1 illustrates the intersection geometry developed with the SIDRA Intersection software. Similarly, signal 
Table 1. Performance measures for the signalized control vs. roundabout control at intersections in small, medium, and large cities.

\begin{tabular}{|c|c|c|c|c|c|c|}
\hline \multirow{2}{*}{ Intersection, truck \% } & \multirow{2}{*}{$\begin{array}{l}\text { Intersection } \\
\text { control }\end{array}$} & \multirow{2}{*}{$\mathrm{LR}^{*}$} & \multirow{2}{*}{ Intersection LOS } & \multirow{2}{*}{$\mathrm{EIC}^{* *}(\mathrm{veh} / \mathrm{hr})$} & \multicolumn{2}{|c|}{$\begin{array}{c}\text { Intersection's annual } \\
\text { performance }\end{array}$} \\
\hline & & & & & Delay (veh-h/y) & Cost $(\$ / y)$ \\
\hline \multicolumn{7}{|c|}{ City of Manhattan, Kansas } \\
\hline \multirow{2}{*}{ Fort Riley Blvd \& Richards Rd, 5.7\% } & Signalized & & $\mathrm{C}$ & 2,916 & 9,040 & 432,088 \\
\hline & Roundabout & Yes & A & 5,727 & 2,597 & 338,010 \\
\hline \multirow{2}{*}{ McCall Rd \& Hays Drive, 8.5\% } & Signalized & & $\mathrm{C}$ & 1,711 & 7,548 & 319,484 \\
\hline & Roundabout & No & A & 4,895 & 1,802 & 234,757 \\
\hline \multirow{2}{*}{ McCall Rd \& Carlson Rd, 4.6\% } & Signalized & & $\mathrm{B}$ & 3,229 & 1,741 & 134,433 \\
\hline & Roundabout & No & A & 6,531 & 829 & 117,662 \\
\hline \multirow{2}{*}{ Seth Childs Rd \& Southwind, 4.3\% } & Signalized & & $\mathrm{D}$ & 3,948 & 19,891 & 713,632 \\
\hline & Roundabout & Yes & A & 6,347 & 4,662 & 482,394 \\
\hline \multirow{2}{*}{ Tutle Creek Blvd \& Kimball, 6.6\% } & Signalized & & $\mathrm{B}$ & 3,062 & 4,858 & 333,376 \\
\hline & Roundabout & Yes & B & 2,919 & 3,061 & 292,332 \\
\hline \multirow{2}{*}{ Tutle Creek Blvd \& McCall Rd, 8.7\% } & Signalized & & B & 3,088 & 4,563 & 327,388 \\
\hline & Roundabout & Yes & A & 5,487 & 1,807 & 279,811 \\
\hline \multicolumn{7}{|c|}{ City of Topeka, Kansas } \\
\hline \multirow{2}{*}{ SW Wanamaker \& Huntoon, 5\% } & Signalized & & $\mathrm{C}$ & 4,084 & 15,919 & 716,747 \\
\hline & Roundabout & No & $\mathrm{B}$ & 5,120 & 6,420 & 560,171 \\
\hline \multirow{2}{*}{ SW Wanamaker \& SW Winding, 5\% } & Signalized & & $\mathrm{C}$ & 3,443 & 15,830 & 630,998 \\
\hline & Roundabout & No & $\mathrm{B}$ & 4,659 & 6,122 & 474,474 \\
\hline \multirow{2}{*}{ SW Wanamaker \& Westridge Mall, 5\% } & Signalized & & $\mathrm{B}$ & 3,918 & 3,853 & 349,141 \\
\hline & Roundabout & No & A & 6,084 & 2,515 & 322,484 \\
\hline \multirow{2}{*}{ Wanamaker \& 17th St, 5\% } & Signalized & & $\mathrm{C}$ & 3,966 & 12,654 & 560,257 \\
\hline & Roundabout & Yes & $\mathrm{B}$ & 4,713 & 4,926 & 435,638 \\
\hline \multirow{2}{*}{ Wanamaker \& 19th St, 5\% } & Signalized & & $\mathrm{C}$ & 2,671 & 11,234 & 492,154 \\
\hline & Roundabout & No & A & 6,119 & 3,265 & 364,537 \\
\hline \multicolumn{7}{|c|}{ City of Overland Park, Kansas } \\
\hline \multirow{2}{*}{ Antioch \& 135, 2\% } & Signalized & & $\mathrm{E}$ & 4,814 & 51,766 & $1,391,678$ \\
\hline & Roundabout & Yes & $\mathrm{D}$ & 4,767 & 41,629 & 123,731 \\
\hline \multirow{2}{*}{ Metcalf \& 75, 2\% } & Signalized & & $\mathrm{F}$ & 5,040 & 140,362 & $2,732,601$ \\
\hline & Roundabout & No & $\mathrm{F}$ & 4,272 & 115,808 & 2,361,954 \\
\hline \multirow{2}{*}{ Nall\& 119, 2\% } & Signalized & & $\mathrm{F}$ & 4,256 & 123,712 & $2,500,024$ \\
\hline & Roundabout & Yes & $\mathrm{F}$ & 4,546 & 103,624 & $2,209,390$ \\
\hline \multirow{2}{*}{ Nall\& College Blvd, 2\% } & Signalized & & $\mathrm{E}$ & 6,308 & 71,590 & $1,846,954$ \\
\hline & Roundabout & Yes & $\mathrm{F}$ & 3,634 & 197,777 & 3,586,945 \\
\hline \multirow{2}{*}{ Roe \& 119, 2\% } & Signalized & & $\mathrm{E}$ & 4,046 & 45,299 & $1,146,175$ \\
\hline & Roundabout & Yes & B & 4,745 & 9,795 & 639,893 \\
\hline \multirow{2}{*}{ Metcalf \& 119, 2\% } & Signalized & & $\mathrm{E}$ & 4,976 & 48,330 & $1,338,656$ \\
\hline & Roundabout & Yes & $\mathrm{D}$ & 5,348 & 30,898 & $1,100,765$ \\
\hline
\end{tabular}

${ }^{*} \mathrm{LR}=$ Approach number of lanes reduced for a roundabout, ${ }^{* *}$ EIC = Effective Intersection Capacity. 
Table 2. Average control delay and emissions for a signalized control vs. roundabout control for small, medium, and large cities.

\begin{tabular}{|c|c|c|c|c|c|c|}
\hline \multirow{2}{*}{ Intersection, truck \% } & \multirow{2}{*}{$\begin{array}{l}\text { Intersection } \\
\text { control }\end{array}$} & \multirow{2}{*}{$\begin{array}{l}\text { Average control delay } \\
\text { (seconds/vehicle) }\end{array}$} & \multicolumn{4}{|c|}{ Emissions (kg/h) } \\
\hline & & & $\mathrm{CO}_{2}$ & $\begin{array}{l}\text { Hydro } \\
\text { carbons }\end{array}$ & $\mathrm{CO}$ & $\mathrm{NO}_{\mathrm{x}}$ \\
\hline \multicolumn{7}{|c|}{ City of Manhattan, Kansas } \\
\hline \multirow{2}{*}{$\begin{array}{l}\text { Fort Riley Blvd \& } \\
\text { Richards Rd, } 5.7 \%\end{array}$} & Signalized & 25.7 & 577.7 & 0.93 & 43.15 & 1.36 \\
\hline & Roundabout & 7.4 & 509.8 & 0.78 & 39.39 & 1.25 \\
\hline \multirow{2}{*}{$\begin{array}{l}\text { McCall Rd \& Hays } \\
\text { Drive, } 8.5 \%\end{array}$} & Signalized & 32 & 408.0 & 0.65 & 29.19 & 0.91 \\
\hline & Roundabout & 7.6 & 351.1 & 0.52 & 26.46 & 0.84 \\
\hline \multirow{2}{*}{$\begin{array}{l}\text { McCall Rd \& Carlson } \\
\text { Rd, } 4.6 \%\end{array}$} & Signalized & 13.7 & 191.5 & 0.31 & 14.56 & 0.46 \\
\hline & Roundabout & 6.5 & 176.3 & 0.27 & 13.28 & 0.43 \\
\hline \multirow{2}{*}{$\begin{array}{l}\text { Seth Childs Rd \& } \\
\text { Southwind, } 4.3 \%\end{array}$} & Signalized & 40.2 & 862.1 & 1.48 & 64.52 & 1.95 \\
\hline & Roundabout & 9.4 & 704.6 & 1.12 & 55.76 & 1.73 \\
\hline \multirow{2}{*}{$\begin{array}{l}\text { Tutle Creek Blvd \& } \\
\text { Kimball, } 6.6 \%\end{array}$} & Signalized & 17.2 & 479.6 & 0.78 & 38.73 & 1.18 \\
\hline & Roundabout & 10.8 & 456.0 & 0.71 & 37.84 & 1.17 \\
\hline \multirow{2}{*}{$\begin{array}{l}\text { Tutle Creek Blvd \& } \\
\text { McCall Rd, } 8.7 \%\end{array}$} & Signalized & 15.8 & 404.1 & 0.63 & 27.58 & 0.83 \\
\hline & Roundabout & 6.3 & 367.3 & 0.54 & 24.22 & 0.75 \\
\hline \multicolumn{7}{|c|}{ City of Topeka, Kansas } \\
\hline \multirow{2}{*}{$\begin{array}{l}\text { SW Wanamaker \& } \\
\text { Huntoon, 5\% }\end{array}$} & Signalized & 29.2 & 953.5 & 1.60 & 75.67 & 2.29 \\
\hline & Roundabout & 11.8 & 847.3 & 1.35 & 69.39 & 2.14 \\
\hline \multirow{2}{*}{$\begin{array}{l}\text { SW Wanamaker \& SW } \\
\text { Winding, 5\% }\end{array}$} & Signalized & 33.7 & 786.6 & 1.38 & 61.54 & 1.84 \\
\hline & Roundabout & 13 & 682.7 & 1.13 & 55.67 & 1.70 \\
\hline \multirow{2}{*}{$\begin{array}{l}\text { SW Wanamaker \& } \\
\text { Westridge Mall, 5\% }\end{array}$} & Signalized & 11.3 & 518.6 & 0.82 & 40.62 & 1.28 \\
\hline & Roundabout & 7.4 & 492.3 & 0.76 & 38.38 & 1.23 \\
\hline \multirow{2}{*}{$\begin{array}{l}\text { Wanamaker \& 17th St, } \\
5 \%\end{array}$} & Signalized & 29.8 & 745.2 & 1.25 & 58.95 & 1.79 \\
\hline & Roundabout & 11.6 & 662.1 & 1.06 & 54.66 & 1.68 \\
\hline \multirow{3}{*}{$\begin{array}{l}\text { Wanamaker \& 19th St, } \\
5 \%\end{array}$} & Signalized & 30.3 & 657.2 & 1.10 & 52.44 & 1.59 \\
\hline & Roundabout & 8.8 & 556.5 & 0.87 & 44.65 & 1.40 \\
\hline & & City of Overland P & Kansas & & & \\
\hline \multirow{2}{*}{ Antioch \& 135, 2\% } & Signalized & 66.4 & $1,518.5$ & 2.78 & 111.44 & 3.30 \\
\hline & Roundabout & 53.4 & $1,440.4$ & 2.58 & 111.82 & 3.29 \\
\hline \multirow{2}{*}{ Metcalf \& 75, 2\% } & Signalized & 158.5 & 2,398.3 & 4.71 & 150.61 & 4.38 \\
\hline & Roundabout & 130.8 & $2,222.5$ & 4.29 & 152.64 & 4.38 \\
\hline \multirow{2}{*}{ Nall\& 119, 2\% } & Signalized & 136.9 & 2,296.0 & 4.46 & 150.74 & 4.38 \\
\hline & Roundabout & 114.7 & $2,149.1$ & 4.10 & 151.47 & 4.44 \\
\hline \multirow{2}{*}{ Nall\& College Blvd, 2\% } & Signalized & 73.2 & $2,003.9$ & 3.70 & 150.72 & 4.38 \\
\hline & Roundabout & 202.4 & $3,053.8$ & 6.12 & 195.26 & 5.49 \\
\hline \multirow{2}{*}{ Roe \& 119, 2\% } & Signalized & 74.7 & $1,209.5$ & 2.23 & 85.55 & 2.56 \\
\hline & Roundabout & 16.2 & 907.7 & 1.52 & 74.45 & 2.26 \\
\hline \multirow{2}{*}{ Metcalf \& 119, 2\% } & Signalized & 60.7 & $1,459.0$ & 2.62 & 101.32 & 3.12 \\
\hline & Roundabout & 38.8 & $1,370.6$ & 2.41 & 109.33 & 3.24 \\
\hline
\end{tabular}




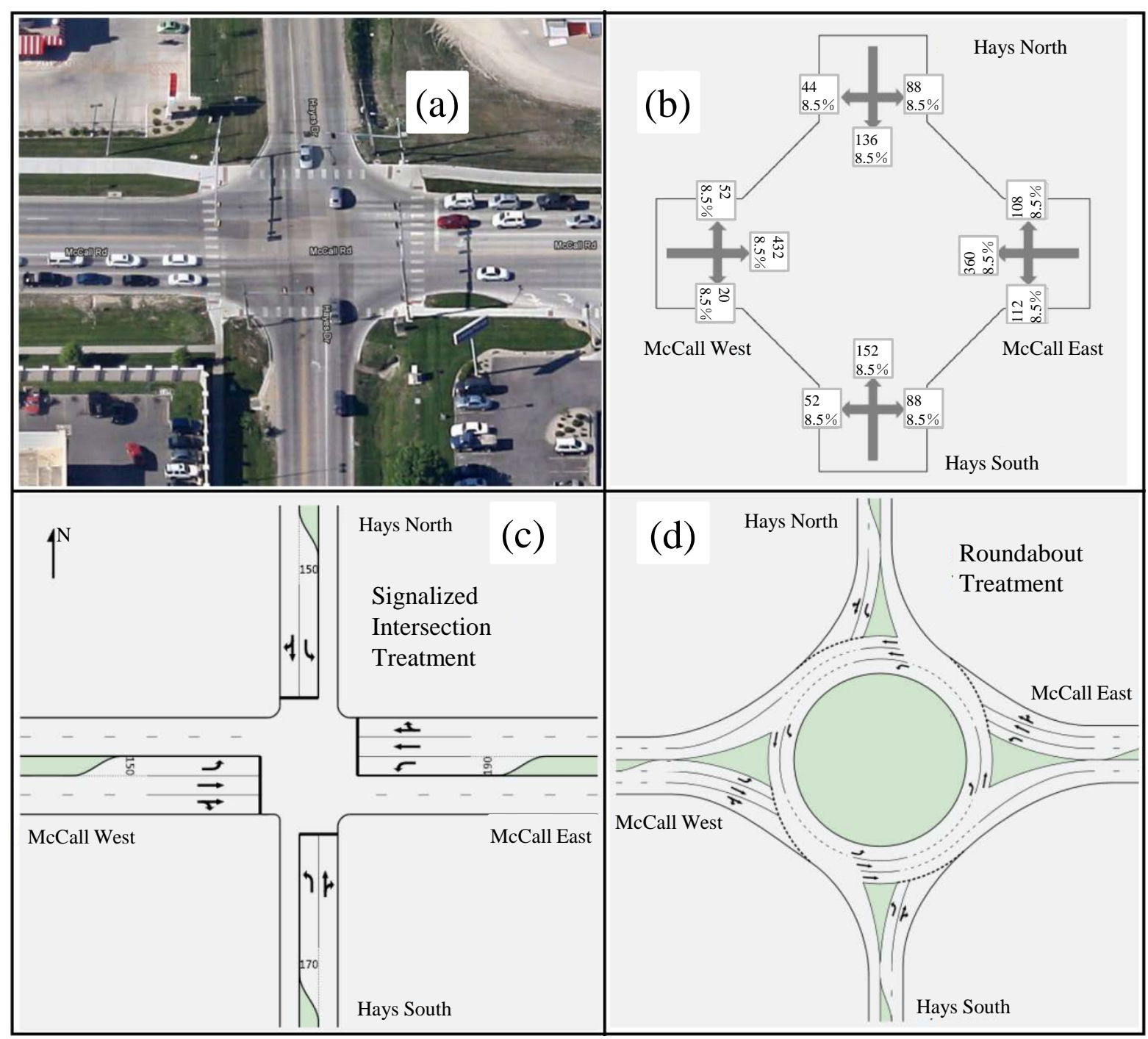

Figure 1. Analysis of the McCall road and Hays drive intersection using the SIDRA Intersection 5.1 software.

phasing and signal timing were designed for the signalized intersection with the SIDRA Intersection software. While the city traffic engineer had traffic-count data available for this intersection, the data were not useful (except for the peak-hour factor data) for the study due to lack of directional traffic counts. Therefore, manual data-counting techniques were used to determine the directional traffic counts and the percentage of trucks for all approaches. Intersection traffic counts and the percentage of trucks counted during one hour were used in the SIDRA Intersection software (illustrated in part c of Figure 1). Other input data that were used for the SIDRA Intersection software included peak-hour factor, the approach cruise speed (speed limit on site), the exiting cruise speed (speed limit on site), queue space for a normal vehicle (a standard of $25 \mathrm{ft}$ was assumed), queue space for a heavy vehicle (truck; a standard of $73 \mathrm{ft}$ was assumed), vehicle length for a normal vehicle (a standard of $17 \mathrm{ft}$ was assumed), and vehicle length for a heavy vehicle (a standard of $73 \mathrm{ft}$ was assumed). Using the above input data, the SIDRA Intersection software was used to analyze the intersection's LOS, the effective intersection capacity, the intersection's annual performance, the average control delay, and the vehicular emissions ( $\mathrm{CO}, \mathrm{HC}, \mathrm{CO}_{2}$, and $\mathrm{NO}_{\mathrm{x}}$ ) for the signalized intersection control at McCall Road and Hays Drive in Manhattan, Kansas. The findings are summarized in Table 1 and Table 2.

The same intersection traffic-count data, percentage of trucks, and all other parameters (except the signal phasing and timing) mentioned above for the signalized-intersection analysis were used to theoretically construct a roundabout at the McCall Road and Hays Drive intersection using the SIDRA Intersection software. A 
standard center-island diameter of $100 \mathrm{ft}$, an entry radius of $100 \mathrm{ft}$, and an entry angle of 30 degrees were used to construct the roundabout in the SIDRA Intersection software. The number of circulating lanes was determined based on the number of left-turn and through-movement lanes for each approach. Also, roundabouts with more than three circulating lanes were not considered in this study because four-lane roundabouts had not been constructed in the United States and were not compatible with the SIDRA Intersection software. Therefore, even when one or more approaches for a signalized intersection had a total number of left-turn and through lanes that was more than three, a three-lane roundabout was designed theoretically, and the signalized intersection was compared to it. A three-lane roundabout (illustrated in part d of Figure 1) was generated using the SIDRA Intersection software for the McCall Road and Hays Drive intersection. The performance measures were calculated using the SIDRA Intersection software and are summarized in Table 1 and Table 2.

It can be observed from Table 1 that the LOS of the McCall Road and Hays Drive signalized intersection (LOS C) was improved by adapting a roundabout control (LOS A). Further, by adapting a roundabout control for the McCall Road and Hays Drive intersection, the average control delay was decreased by $76.3 \%$ (Table 2), the intersection's annual delay was decreased by $76.1 \%$ (Table 1), and the intersection's annual cost decreased by $26.5 \%$ (Table 1) when compared to a signalized control. Vehicle emissions, such as $\mathrm{CO}, \mathrm{HC}, \mathrm{CO}_{2}$, and $\mathrm{NO}_{\mathrm{x}}$, were decreased by $13.9 \%, 20 \%, 9.4 \%$, and $7.7 \%$, respectively. Therefore, it can be understood that, at the McCall Road and Hays Drive intersection, which has significant truck traffic (8.5\% of total traffic), a roundabout control instead of a signalized control can improve traffic flow (better LOS), reduce congestion (observed reduction in the delay), and enhance air quality in and around the communities (observed reduction in emissions) which can then facilitate optimum goods movement in Manhattan's urban freight-roadway network.

\subsection{Medium City: Topeka, Kansas}

Officials from the city of Topeka did not respond to the request for acquiring data about city freight-roadway networks, intersections with a high truck volume, or intersection traffic counts. Therefore, traffic counts for five of Topeka's major intersections (listed in Table 1) in were obtained from Mr. Dean Landman and Dr. Eugene Russell's [17] previous studies, and the intersection control at these five intersections was a signalized control. These five signalized intersections, with their traffic counts, were used for the study assuming that $5 \%$ of the total vehicles were trucks.

Intersection analysis was performed using the SIDRA Intersection software for all five selected intersections by testing the effectiveness of the signalized control vs. roundabout control, and the results are presented in Table 1 and Table 2. It can be summarized from Table 1 and Table 2 that, for all the five intersections that were studied in Topeka, the roundabout control proved to have a better LOS, more effective intersection capacity, less control delay, fewer emissions, and better annual intersection performance when compared to the signalized control.

\subsection{Big City: Overland Park, Kansas}

The City of Overland Park had a freight roadway network that was already developed; therefore, the task of selecting intersections for this city was simple. Based on discussions with the city traffic engineer for Overland Park, Mr. Brian Shields, and based on the traffic data availability from the city for this study, six signalized intersections (listed in Table 1) were selected as optimum for studying the performance comparison between the signalized intersection control that was present and a roundabout control that was theoretically created using the SIDRA Intersection software. Directional traffic counts, signal phasing, and signal timing data were provided by the city traffic engineer's office. A $2 \%$ truck usage among the total vehicles utilizing these six intersections was suggested by the city traffic engineer for the performance-comparison computations.

Intersection analysis was performed using the SIDRA Intersection software for all six selected intersections in order to test the effectiveness of signalized intersection control and roundabout control; the results were presented in Table 1 and Table 2. From the six selected intersections in Overland Park, it was observed that the current intersection geometry would require designing four-lane or five-lane roundabouts, which the authors considered to not be practical at this time in the United States. Therefore, for such situations, the roundabout design was downgraded to a three-lane roundabout, and the performance was measured and compared with signalized intersections. Among the six intersections, roundabout designs were downgraded for five intersections by designing a three-lane roundabout which might bring down the roundabout's benefit trend. While there have 
been intersection annual-cost benefits, and interaction annual-delay benefits observed for all six intersections with a roundabout control, average control delay benefits, emission-reduction benefits, and effective intersectioncapacity benefits observed for less than six intersections with a roundabout control, the benefits were not significant and consistent among all the intersections considered. Further, the LOS for a roundabout control in five of the six intersections considered was either equal to or lower than the LOS observed for a signalized intersection control. One reason for the poor performance of roundabout control in this city can be attributed to the fact that five of the six selected intersections were designed with a smaller number of lanes than were originally present on site with the signalized intersection control. Control delays and vehicular emissions, such as $\mathrm{CO}, \mathrm{HC}, \mathrm{CO}_{2}$, and $\mathrm{NO}_{\mathrm{x}}$, were used as performance measures to make conclusions about the most effective intersection control.

\subsection{Statistical Analysis for Testing the Performance Measures for Signalized and Roundabout Intersection Control in Urban Freight-Roadway Networks}

Average control delay and vehicular emissions, such as $\mathrm{CO}, \mathrm{HC}, \mathrm{CO}_{2}$, and $\mathrm{NO}_{\mathrm{x}}$, were considered to be critical in the study to determine the optimum intersection control. A randomized complete-block design statistical analysis was conducted for the selected intersections in Manhattan, Topeka, and Overland Park in order to determine the desirable intersection control that can be used with urban freight-roadway networks. For this randomized complete-block design analysis, the experimental units are stratified into homogeneous blocks. Each intersection control type is randomly assigned to an equal number of experimental units for each block such that a precise comparison between the intersection control types can be made within the experimental units. Figure 2 illustrates the design layout for intersections in Manhattan, Kansas. Each city's selected intersections were used as blocks, such that any difference in the response (average control delay or emissions) caused by a specific intersection control can be associated with the blocks. It was assumed that there is no interaction between the intersection control types and the intersections. The randomized complete-block design experiment was conducted multiple times with various response variables, such as average control delay, CO emissions, HC emissions, $\mathrm{CO}_{2}$ emissions, and $\mathrm{NO}_{\mathrm{x}}$ emissions.

Statistical Model for the Randomized Complete Blocks [18]: The linear model for this study can be written as

$$
Y_{i j}=\mu+\tau_{i}+b_{j}+e_{i j} \text {, where } i=1, \cdots, t \text { and } j=1,2, \cdots, b
$$

1) $Y_{i j}$ is the observed response [for example: observed control delay (in seconds/vehicle)] for the $i^{\text {th }}$ intersection type with respect to the $j^{\text {th }}$ intersection.

\begin{tabular}{|c|c|c|}
\hline - For $\mathrm{I}$ & Treatments : Inte & tion Type \\
\hline $\begin{array}{l}\text { Block 1: } \\
\text { Fort Riley Blvd \& Richards Rd }\end{array}$ & $\begin{array}{l}\text { Signalized } \\
\text { Intersection }\end{array}$ & Roundabouts \\
\hline $\begin{array}{c}\text { Block 2: } \\
\text { McCall Rd \& Hays Dr }\end{array}$ & $\begin{array}{l}\text { Signalized } \\
\text { Intersection }\end{array}$ & Roundabouts \\
\hline $\begin{array}{c}\text { Block 3: } \\
\text { McCall Rd \& Carlson Rd }\end{array}$ & $\begin{array}{l}\text { Signalized } \\
\text { Intersection }\end{array}$ & Roundabouts \\
\hline $\begin{array}{c}\text { Block 4: } \\
\text { Seth Childs Rd \& Southwind }\end{array}$ & $\begin{array}{l}\text { Signalized } \\
\text { Intersection }\end{array}$ & Roundabouts \\
\hline $\begin{array}{l}\text { Block 5: } \\
\text { Tuttle Creek Blvd \& Kimball }\end{array}$ & $\begin{array}{l}\text { Signalized } \\
\text { Intersection }\end{array}$ & Roundabouts \\
\hline $\begin{array}{c}\text { Block 6: } \\
\text { Tuttle Creek Blvd \& Mccall Rd }\end{array}$ & $\begin{array}{l}\text { Signalized } \\
\text { Intersection }\end{array}$ & Roundabouts \\
\hline
\end{tabular}

Figure 2. Randomized complete-block design layout for Manhattan intersections. 
2) $\mu$ is the overall mean response (for example: overall mean control delay measured in seconds/vehicle).

3) $\tau_{i}$ is the fixed effect of $i^{\text {th }}$ intersection type on the response.

4) The random block effect, $b_{j}$, represents the effect of intersection $\mathrm{j}$ on the response, with mean 0 and variance $\sigma_{b}^{2}$.

5) $E_{i j}$ is the experimental error which is independently and identically distributed (IID) as a normal distribution, with mean 0 and variance $\sigma^{2}$.

The results from the hypothesis testing are summarized in Table 3, and it was concluded that statistically significant results were observed for a reduction in the average control delay and vehicle emissions $\left(\mathrm{CO}, \mathrm{HC}, \mathrm{CO}_{2}\right.$, and $\mathrm{NO}_{\mathrm{x}}$ ) when theoretically implementing a roundabout control at intersections for freight roadway networks instead of having a signalized control for small and medium cities. Although of limited universal application, using a series of roundabouts on freight routes, or routes with a large number of trucks, is something the authors believe has never been studied and/or published; the local results show that the roundabouts in Kansas' small and medium cities' freight roadway networks can reduce the drivers' delay, thereby decreasing congestion and improving the traffic flow. It can also be concluded that the emissions were decreased by implementing a roundabout control for small and medium cities' urban, freight intersections, leading towards a better environment. While statistically significant results were observed for the average control delay reduction with a roundabout control instead of a signalized control in a big city, statistically significant results were not observed for vehicular emissions. It has to be understood that, as the city's size increases, the intersections' complexity increases for urban freight-roadway networks, necessitating the usage of multiple lanes for improved traffic management which is when roundabout installation might get challenging and might not be possible.

\section{Conclusions and Recommendations}

This study has analyzed integrating the greater use of roundabouts for freight roadway networks in and around urban areas in order to optimize goods movements as well as to decrease vehicle delays, congestion, and emissions, thus enhancing air quality in and around the communities. For this purpose, three different cities (Manhattan as a small city, Topeka as a medium-sized city, and Overland Park as a big city) in Kansas were considered to analyze the effectiveness of roundabout control for freight roadway networks when compared to a signalized control.

It was concluded that the roundabouts in Kansas' small and medium cities' freight roadway networks could reduce the delay for the trucks and other vehicles, could decrease congestion, and could contribute to improved traffic flow. It could also be concluded that emissions were reduced, decreasing air pollution, by implementing a roundabout control for small and medium cities' urban freight-route intersections. Statistically significant results were also observed for decreased average control delay and reduced vehicular emissions $\left(\mathrm{CO}, \mathrm{HC}, \mathrm{CO}_{2}\right.$, and $\mathrm{NO}_{\mathrm{x}}$ ) by implementing a roundabout control with freight roadway networks for selected intersections in small and medium-sized cities.

For selected intersections in Overland Park, the roundabout control did not yield a statistically significant result to conclude that they decreased emissions when compared to a signalized control. As discussed in the body of this paper, these results could be due to a small sample, the limitations with the number of lanes that are practical at this time in the United States, and the limitations for the software version used. Due to the design limitations for the large-city example used in this study, the results about the benefits of integrating roundabouts into freight roadway networks in large cities were inconclusive. It is recommended that additional, more comprehensive studies be conducted to verify the potential benefits.

Table 3. Results from the randomized complete-block design analysis.

\begin{tabular}{cccc}
\hline \multirow{2}{*}{ Performance measure } & \multicolumn{3}{c}{ Statistically significant reduction observed with roundabout control instead of a signalized control? } \\
\cline { 2 - 4 } Average control delay & Manhattan & Topeka & Overland Park \\
$\mathrm{CO}_{2}$ emissions & Yes & Yes & Yes \\
$\mathrm{HC}$ emissions & Yes & Yes & No \\
$\mathrm{CO}$ emissions & Yes & Yes & No \\
$\mathrm{NO}_{\mathrm{x}}$ & Yes & Yes & No \\
\hline
\end{tabular}


It has to be understood that all intersections on an urban freight-roadway network may not be suitable for roundabout control; by implementing roundabout control at a few locations, the overall freight movement and emissions can be optimized. In this study, the city engineers have guided the selection of intersections which are suitable locations for a performance comparison of the current intersection control with a theoretical roundabout control. While the results obtained from the SIDRA Intersection software are reliable, it is recommended that the emission results obtained from the software output should be checked with a U.S. field study to validate the results.

\section{Acknowledgements}

The authors would like to acknowledge Mr. Brian Shields and Mr. Dean Landman for providing useful data for this study.

\section{References}

[1] Cambridge Systematics and Battelle Memorial Institute (2005) An Initial Assessment of Freight Bottlenecks on Highways, Federal Highway Administration.

[2] Office of Freight Management and Operations (2009) Freight Facts and Figures, Federal Highway Administration.

[3] Cambridge Systematics and Texas Transportation Institute (2004) Traffic Congestion and Reliability: Linking Solutions to Problems, Federal Highway Administration.

[4] Rodegerdts, L., Bansen, J., Tiesler, C., Knudsen, J., Myers, E., Johnson, M., Moule, M., Persaud, B., Lyon, C., Hallmark, S., Isebrands, H., Crown, R.B., Guichet, B. and O’Brien, A. (2010) Roundabouts: An Informational GuideSecond Edition. NCHRP Report 672, Transportation Research Board of the National Academics, Washington DC.

[5] Russell, E.R., Luttrell, G. and Rys, M. (2002) Roundabout Studies in Kansas. 4th Transportation Specialty Conference of the Canadian Society for Civil Engineering, Canada.

[6] Russell, E.R., Mandavilli, S. and Rys, M. (2005) Operational Performance of Kansas Roundabouts: Phase II. Report No: K-TRAN: KSU-02-4.

[7] Gingrich, M. and Waddell, E. (2008) Accommodating Trucks in Single and Multilane Roundabouts. Transportation Research Board, National Roundabout Conference, Kansas City, 12-18 May 2008.

[8] Godavarthy, R.P. (2012) Network and Design Concepts for Accommodating Large Trucks at Roundabouts. Ph.D. Dissertation, Kansas State University.

[9] Godavarthy, R.P., Russell, E.R. and Landman, D. (2012) Accommodating Oversize/Overweight Vehicles at Roundabouts: Survey Results and Preliminary Designs. Research in Agricultural \& Applied Economics.

[10] Godavarthy, R. and Russell, E. (2015) Low-Clearance Truck’s Vertical Requirements at Roundabouts. Journal of Transportation Technologies, 5, 214-222. http://dx.doi.org/10.4236/jtts.2015.54020

[11] Russell, E.R., Landman, D. and Godavarthy, R.P. (2013) A Study of Accommodating Oversize Overweight Vehicles (OSOW) at Roundabouts. Transportation Research Board Annual Meeting: Compendium of Papers, Washington DC.

[12] Russell, E.R., Landman, D. and Godavarthy, R.P. (2013) Accommodating Oversize Overweight Vehicles at Roundabouts. Report No. K-TRAN: KSU-10-1, Kansas Department of Transportation.

[13] Russell, E.R., Landman, D. and Godavarthy, R.P. (2013) Key Findings and Conclusions from the Study: Accommodating Oversize/Overweight Vehicles at Roundabouts. 2013 Conference and Exhibition of the Transportation Association of Canada-Transportation: Better-Faster-Safer.

[14] Mandavalli, S., Rys, M.J. and Russell, E.R. (2008) Environmental Impact of Modern Roundabouts. International Journal of Industrial Ergonomics, 38, 135-142. http://dx.doi.org/10.1016/j.ergon.2006.11.003

[15] United States Environmental Protection Agency (2008) Idling Vehicle Emissions for Passenger Cars, Light-Duty Trucks, and Heavy Duty Trucks, EPA420-F-08-025.

[16] SIDRA INTERSECTION 5.1 Version Software (2012) SIDRA INTERSECTION User Guide. http://www.sidrasolutions.com/downloads/SIDRAINTERSECTION_UserGuide.pdf

[17] Russell, E.R., Landman, D. and Godavarthy, R.P. (2012) A Study of the Impact of Roundabouts on Traffic Flows and Business. Report No. K-TRAN: KSU-09-10, Kansas Department of Transportation.

[18] Kuehl, R.O. (1994) Statistical Principles of Research Design and Analysis. Duxbury Press. 